\section{Integrating the}

National

Intelligence

Model with a

'problem

solving'

\section{approach}

\author{
Stuart Kirby
}

Detective Chief

Superintendent with the

Lancashire Constabulary

\section{Ian McPherson}

Assistant Chief Constable 'Operations' with the Merseyside Police Force and chairs the ACPO working group on problem solving

\section{KEY WORDS}

\section{intelligence}

problem solving

analysis

partnership

\section{ABSTRACT}

The National Intelligence Model, described as a 'model for policing', defines a process for setting priorities and a framework in which problem solving can be applied. Its strength is a systematic approach that demands standard products and consistent methods of working, which ensure high levels of ownership and accountability. The problem solving approach can also work within this framework. It provides techniques to assist in analysis and develops the tasking and co-ordinating mechanism through multi-agency partnerships, which can deliver more sustainable solutions.

\section{INTRODUETION}

The requirement for the police to work alongside partners to tackle crime and disorder is made out in Government policy and legislation, and is also endorsed by Her Majesty's Inspectorate of Constabulary (HMIC) as well as the Association of Chief Police Officers (ACPO). However whilst the majority of police forces explicitly support this approach there is considerable evidence to show that implementation has not been systematic (see Bullock \& Tilley, 2003), which has resulted in a considerable waste of resources.

The ACPO working group on 'problem solving' was formed with the overall purpose of assisting forces to use problem oriented approaches to make sustainable reductions in the fear and actual levels of crime and disorder in the most cost-effective way. The group started by conducting a present position survey of the 43 police forces in England and Wales, in relation to their use of problem solving approaches. Amongst its findings practitioners reported considerable confusion as to how problem oriented approaches integrated with the National Intelligence Model (NIM); a finding corroborated by academics monitoring NIM implementation. As John and Maguire (2003: 39) reported, 'As POP is already well established in several forces, the compatibility of the two models may have an impact upon the implementation of the NIM and how easily it is accepted and understood by officers on the ground'.

This abridged paper, which comes from a much larger piece of work prepared in conjunction with the Police Standards Unit, is an attempt to provide clarity in this area and will show that both methods have strengths that complement each other. The sections that follow show how each depend on an infrastructure to succeed, how they both support a tiered response and finally how a problem solving approach such as SARA 
(Scanning, Analysis, Response and Assessment) can integrate seamlessly into the National Intelligence Model.

\section{AN INITIAL POINT ABOUT INFRASTRUCTURE}

Implementation failure (see

Crawford, 1998) is a well-

documented concept within the

field of community safety. A focus on 'what works' has provided a plethora of evidence to show that good ideas need to be supplemented by sound practice if crime reduction programmes are to succeed. For instance the programme may fail due to the theory being impracticable in a particular environment ie, the practitioner not having the inclination, skills or time to deliver. On other occasions the resources may not be in place to implement the initiative as envisaged; or no evaluation criteria was put in place to show whether the programme or initiative worked. These issues have been articulated in many papers (see Read \& Tilley, 2000; Kirby, 2003), and will not be further discussed here. The point is that programme failure often materialises through a deficiency in preparing the infrastructure that supports the approach. This is especially true of problem solving approaches. During the survey mentioned earlier representatives of invited forces were asked to articulate the enablers or blockages to successful problem solving approaches. A further paper will outline these issues, however they include:

- leadership: investment and commitment for the approach

- people: focusing on setting objectives, skills, training and performance management

- systems and processes: which include clear and robust processes at strategic and tactical levels for analysis, prioritisation, sharing and co-ordinating responses as well as assessment.

In contrast the NIM has acknowledged these issues from the outset by setting out the infrastructure requirements. Indeed the National Intelligence Model makes explicit reference to assets in the areas of people, knowledge, systems and information although John and Maguire (2003) also identified implementation difficulties during the initial roll out.

\section{A TIERED APPROACH TO PROBLEM SOLVING AKDTHE NATIONAL INTELLGENGE MODEL}

Further similarities can be seen

between the two approaches in relation to the levels on which they operate. Goldstein (1990) spoke of a tiered approach to problem solving, extending from individual problem solving at beat or neighbourhood level to more strategic problem solving at local government or national level.

The NIM provides a wellstructured mechanism for this approach providing three tiers of analysis and response. Level 1 deals with issues of crime and anti-social behaviour at Basic Command Unit (BCU) level and below. Level 2 deals with offender(s), or other specific issues, that cross borders into neighbouring $\mathrm{BCU}$ or force areas and whilst these issues may be similar to those at level 1 , there is a likelihood that a more coordinated cross border response will be required. Finally level 3 deals with serious and organised crime, as well as security matters on a national or international scale.

Therefore whilst problemoriented approaches advocate a tiered response, the NIM explicitly articulates how it can be achieved. This in theory allows a joined up approach between local and national policing issues and since this approach has been forged there has been an increase in regional and force collaboration across a range of issues. In essence it provides a model for managers at all levels.

\section{INTEGRATING A PROBLEM SOLVING MODEL [SARA] WITH THE NATIONAL INTELIIGENGE MODEL}

A small number of articles have now appeared concerning the 
compatibility between the NIM and problem oriented approaches. Whilst some continue to watch developments with interest (Tilley, 2003), crime analysts such as Billsborough and Keay (2002), have highlighted the benefits of the approaches working in tandem. The following section aims to show the compatibility of the two approaches in more detail by using the SARA model, an acronym for Scanning (identifying the problem); Analysis (what causes the problem to occur); Response (typically a multi-agency response aimed at delivering sustainable solutions by tackling underlying causes) and Assessment (which looks at whether the initiative was properly implemented and whether it had an impact).

As this paper is predominantly designed to establish whether the NIM can facilitate problem solving techniques it will use the SARA model to show the links to the NIM (rather than vice versa). It must be mentioned however that whilst SARA is perhaps the most widely known of the problem solving models others are equally applicable ie, the 5i's framework (Intelligence, Intervention, Implementation, Involvement and Impact) - see http://www.crimereduction.gov.uk/to olkits/ui00.htm for further information on this model.

\section{SCANNING AND HOW IT RELATES TO THE NIM}

The commencement of any problem solving approach requires accurate identification of the problem prior to analysis. Information gathering is paramount to problem identification. The information should provide a systematic description of problem type and recurring problems. It should confirm that the problem exists, determine how frequently it occurs and identify the consequences. Experience has also shown that partners need to break down large, vague problems such as the 'drug problem' or 'disorder' into smaller more defined problems in order that they can be effectively analysed. In practice problemoriented approaches have supported an eclectic approach to information gathering although they have provided little advice on how priorities should be set.

It is here that the National Intelligence Model provides immediate benefits. As John and Maguire (2003: 38) state: '[The NIM] is in essence a business model - a means of organising knowledge and information in such a way that the best possible decisions can be made about how to deploy resources, that actions can be co-ordinated within and between different levels of policing, and that lessons are continually learnt and fed back into the system.'
As such the NIM outlines how the problem identification process should take place. It offers a framework to gather internal, external, open, community and multi-agency information which feeds into four key intelligence products that inform the Tasking and Coordinating Group (TCG) of existing problems. These products are known as the strategic assessment (which is the principle document that the strategic group uses to define priorities); the tactical assessment from which the tactical group sets the menu of responses; target profiles (which focus on people) and problem profiles, which focus on areas (hot spots), or themes (ie, crack cocaine).

The concept of scanning (or problem identification), set out in SARA is therefore consistent with the collation of information within the NIM. From these key intelligence products the Strategic Tasking and Coordinating Group (STCG) sets a control strategy, which identifies the priorities that are to be the subject of intelligence, prevention and enforcement responses. These priorities can be reviewed and updated throughout the year and are set at levels 1 (BCU), 2 (cross border) and 3 (national).

However once the priorities have been highlighted further work needs to be undertaken in order that the problem can be dealt with. The next section covers this process. 


\section{ANALYSIS AND HOW IT RELATES TO NIM}

Scott (2000: 7), reviewing

developments in problem oriented

policing over the past 20 years said

'Problem analysis remains the

aspect of the concept most in need

of improvement. This is partly due

to inadequate resources and weak analysis methods, but it is also due to the different ways in which the police and researchers understand how analysis contributes to addressing problems.' As such analysis cannot be over emphasised. If the analysis is flawed, subsequent prioritisation and response will be both inappropriate and ineffective.

There has been considerable discussion on the level of expertise provided by analysts within policing and community safety especially when their product has been the reproduction of statistics rather than to provide analysis. When sufficient information is available to identify and understand the problem practitioners should be encouraged to formulate a hypothesis that directs further analysis. Such a hypothesis determines the types of data to collect, how the data should be analysed, and how to interpret the results. Table 1 shows three such examples.

To assist in analysis problem oriented approaches have

\section{Table 1 'Become a Problem Solving Analyst' (Clarke \& Eck, 2003)}

\begin{tabular}{|c|c|c|}
\hline \multicolumn{3}{|c|}{ Questions, hypotheses and tests } \\
\hline Question & Example hypothesis & Possible test \\
\hline $\begin{array}{l}\text { 1. Why does this } \\
\text { hot spot occur? }\end{array}$ & $\begin{array}{l}\text { This hot spot is due to } \\
\text { a large number of } \\
\text { targets being available. }\end{array}$ & $\begin{array}{l}\text { Count the number of targets in the } \\
\text { hot spot and calculate the crime } \\
\text { rate. Compare this rate to rates for } \\
\text { the surrounding area. If the hot } \\
\text { spot rate is higher (fewer } \\
\text { crimes/vehicles), the hypothesis is } \\
\text { false, but if it is about the same or } \\
\text { lower then the hypothesis is true. }\end{array}$ \\
\hline $\begin{array}{l}\text { 2. Why are there } \\
\text { more car thefts in } \\
\text { the problem area } \\
\text { than in nearby } \\
\text { areas? }\end{array}$ & $\begin{array}{l}\text { Problem area residents } \\
\text { are more likely to park } \\
\text { their cars on the street } \\
\text { than residents of the } \\
\text { other areas. }\end{array}$ & $\begin{array}{l}\text { If the problem area has similar or } \\
\text { lower on-street parking rates to the } \\
\text { others, reject the hypothesis. If } \\
\text { higher, accept it. }\end{array}$ \\
\hline $\begin{array}{l}\text { 3. Why did the } \\
\text { theft of copper } \\
\text { piping from new } \\
\text { construction } \\
\text { suddenly increase? }\end{array}$ & $\begin{array}{l}\text { It increased when a } \\
\text { scrap metal dealership } \\
\text { was sold to a new } \\
\text { owner. }\end{array}$ & $\begin{array}{l}\text { Compare the thefts of copper } \\
\text { piping for periods of time before } \\
\text { and after the change in owners. } \\
\text { If the theft rate is the same before } \\
\text { and after, or the trend in thefts was } \\
\text { already going up before the } \\
\text { change, then the hypothesis is } \\
\text { probably false. If otherwise, the } \\
\text { hypothesis appears reasonable. }\end{array}$ \\
\hline
\end{tabular}

\section{Figure 1 The Problem Analysis Triangle}

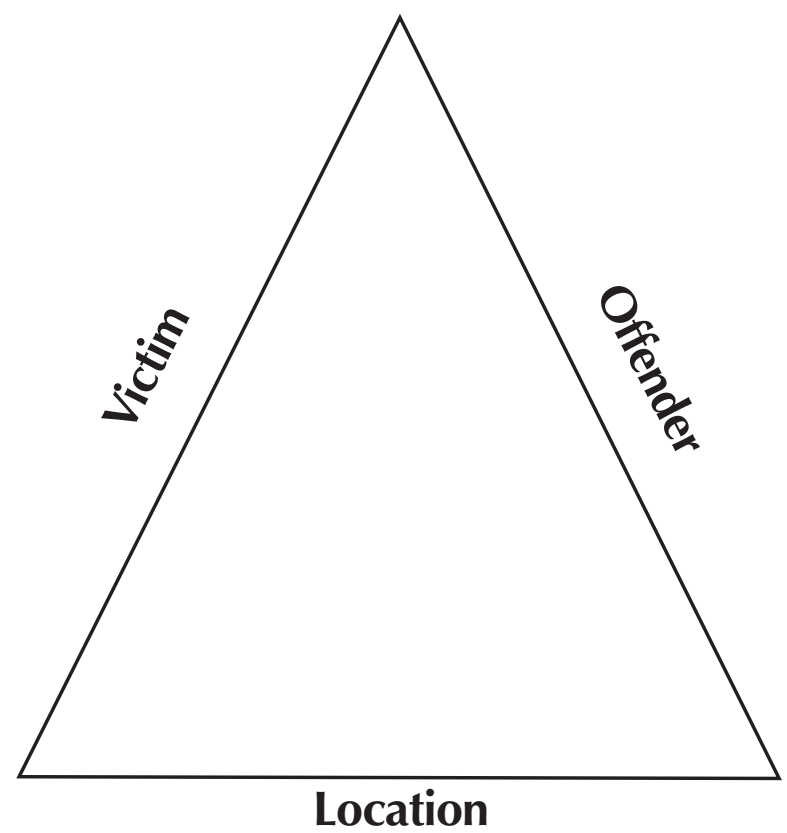


developed and used a range of techniques. One of these is shown

in Figure 1, The Problem Analysis Triangle (PAT), which focuses on the features or characteristics of the victim, offender or location and the level each plays in creating or sustaining the problem. The concept argues that if any of the three issues is effectively taken away, the problem (symbolised by the triangle) is reduced. There is considerable advice in the problem solving literature on how to use this.

Analysis is also fundamental to the NIM. The model describes nine analytical products and techniques that provide a sophisticated means of problem analysis to develop the key intelligence products mentioned in the scanning section earlier. These products are applicable to each of the three operating levels of the NIM and when integrated with the victim, offender, location components can provide a substantive analytical base. For those more acquainted with problem oriented approaches the analytical products outlined in the NIM are briefly described below:

- Crime pattern analysis: A generic term for a number of related disciplines, such as crime or incident series identification, crime trend analysis, hot spot analysis and general profile analysis. A major contributor when applied to problem solving in both scanning and analysis, it can reveal linkages between offences or problems.

- Network analysis: Describes not just the linkages between people who form criminal networks, but also the significance of the links.

- Criminal business profile: These profiles contain detailed analysis of how criminal operations or techniques work, in the same way that a legitimate business may be explained. The application of such profiles to the problem analysis triangle will focus on the offender facet. The analysis can be used to identify key points for investigation, disruption, or highlight crime prevention and reduction opportunities.

- Demographic/social trends analysis: This is a technique for medium/ longer term problem solving as it is centred on demographic changes and the impact on the victim, offender and location. It also allows deeper analysis of social factors such as unemployment and homelessness. It considers the significance of population shifts, attitudes and activities. Partnership development may benefit from this technique as a predictive tool to anticipate future developments in respect of transient/migratory populations and the likely impact on the surrounding area/economy.

- Market profiles: A market profile surveys the criminal market around a particular commodity or service 'craved' by offenders. Craved is used as an acronym for concealable, removable, available, valuable, enjoyable and disposable (Clarke, 1999).

- Target profile analysis: As research shows, a small number of offenders commit a disproportionate level of crime and disorder. Analysis of the target should be wide enough to be fully exploited by a multiagency problem solving approach.

- Risk analysis: Risk analysis covers the duty of care in law enforcement, the requirement to manage persistently dangerous offenders and the implications of the Human Rights Act. Risk analysis therefore assesses the scale of risk posed by offenders or organisations to individual victims, the public at large, and agencies. Tactically it will be of value in helping judge the likely consequences of any level of problem solving activity. Risk analysis applied through the 'PAT' can indicate the nature and consequence of potential response.

There are two other analytical products known as 'operational 
intelligence assessment' and 'results analysis'; these will both be discussed in the assessment section.

We therefore see that the problem solving methodology provides different techniques to supplement the NIM in analysing the problem and therefore providing, for example, more effective target or problem profiles. The problem solving methodology integrated with the NIM analytical tools create standard analytical products, which can raise use and quality across the country. However even with a good understanding of the issue action still has to be taken to eradicate or reduce it.

\section{RESPONSE AND HOW IT RELATES TO THE NIM}

In any problem-oriented approach the response should counteract the factors that are causing the problem. These should be based on approaches that are known to work. Response should also take cognisance of how other agencies/ partnerships/ communities could respond to deliver a sustainable solution. This demands a higher level of professional knowledge not only in terms of 'what works' but also the capacity and capability of others.

Other problem solving models such as the ' $5 \mathrm{i}$ 's' (mentioned earlier) provide more detailed mapping of the response stage (intervention, implementation and involvement).

\section{"We therefore SEE that \\ THE PROBLEM SOLVING METHODOLOGY PROVIDES \\ DIFFERENT TECHNIQUES TO SUPPLEMENT THE NIM IN ANALYSING THE PROBLEM AND THEREFORE PROVIDING, FOR EXAMPLE, MORE EFFECTIVE TARGET OR PROBLEM PROFILES."}

This captures more information to ensure high quality of action and the most successful forms of implementation, partnership and mobilisation of the community. However whatever the planned response it requires implementation and this is where difficulties are often found.

As such the tasking and coordinating process within the NIM model provides an accountability mechanism for practitioners to deliver workable responses. The tactical response menu within the NIM emanates from three approaches: intelligence, enforcement and prevention, which can be further sub-divided to provide many alternative interventions. As their name suggests the tasking and coordinating groups at strategic and tactical level make sure activity is both relevant and focused with the subsequent action plan identifying roles/responsibilities and the objective to be achieved. Tasking and coordinating mechanisms with partner agencies provide obvious tensions and requires understanding from those taking part. However the potential for joint action groups at strategic and tactical levels offers much potential to deliver sustainable solutions.

Some have criticised the NIM because it focuses too much on enforcement (also an important tool in problem solving). Here again is where the problem solving methodology can add value by integrating situational crime prevention into the NIM framework. Situational crime prevention has been the single most important development to reinforce and inform the problem solving approach. It suggests that as the number of criminal opportunities rise, so crime rises and conversely, as the numbers of criminal opportunities are reduced, crime is reduced. Therefore it focuses crime prevention toward more situation specific methods of opportunity blocking, basically convincing offenders that committing a particular crime in a particular place at a particular time is not worthwhile. The approach suggests specific crime problems need to be analysed to guide contextually specific solutions. For those with limited knowledge of its potential it is described further. 


\section{"SituATIONAL CRIME \\ PREVENTION HAS BEEN THE \\ SINGLE MOST IMPORTANT \\ DEVELOPMENT TO \\ REINFORCE AND INFORM \\ THE PROBLEM SOLVING \\ APPROACH."}

\section{SITUATIONAL GRIME REDUGTION AND TARGET HARDENING IN PRACTICE}

This approach outlines a range of situational techniques (including the management and manipulation of the environment and the perception of the potential offender) to reduce the opportunity for crimes to be committed. There is a considerable body of evidence to show this is effective in reducing crime in a range of circumstances. It provides a cost effective sustainable solution, as it does not rely on enforcement, which often delivers more shortterm results. Table 2 highlights five opportunity-reducing techniques that have been subdivided into alternative tactics to show the flexibility of this approach.

These interventions continue to develop and recently the problem analysis triangle has been used to assist the response as well as analysis. Figure 2 shows that the over-laying triangle can suggest interventions that may have a beneficial impact on the

\begin{tabular}{|c|c|}
\hline \multicolumn{2}{|c|}{$\begin{array}{l}\text { Table } 2 \text { Adapted from Clarke, } 1997 \text { and Clarke and Eck, } \\
2003\end{array}$} \\
\hline Technique & Examples \\
\hline \multicolumn{2}{|l|}{ 1. Increase the effort of crime } \\
\hline Harden targets & $\begin{array}{l}\text { Screens for bus drivers and other staff } \\
\text { dealing with money } \\
\text { Strengthen targets eg, ticket machines or } \\
\text { phone booths } \\
\text { Introduction of steering wheel locks }\end{array}$ \\
\hline Control access to targets & $\begin{array}{l}\text { Entry phones on apartments } \\
\text { Alley gates } \\
\text { Electronic tags on goods } \\
\text { Ticket barriers at train stations }\end{array}$ \\
\hline Deflect offenders from targets & $\begin{array}{l}\text { Keeping football fans segregated } \\
\text { Reducing congestion } \\
\text { Street design }\end{array}$ \\
\hline Control crime facilitators & $\begin{array}{l}\text { Toughened glass } \\
\text { Photos on credit cards }\end{array}$ \\
\hline \multicolumn{2}{|l|}{$\begin{array}{l}\text { 2. Increase the perceived risks } \\
\text { of crime }\end{array}$} \\
\hline Screen entrances and exits & Electronic ticket barriers \\
\hline Formal surveillance & $\begin{array}{l}\text { CCTV } \\
\text { Security guards } \\
\text { Alarms }\end{array}$ \\
\hline Surveillance by employees & $\begin{array}{l}\text { Training employees } \\
\text { Rewarding vigilance }\end{array}$ \\
\hline Natural surveillance & $\begin{array}{l}\text { Street lighting } \\
\text { Defensible space architecture }\end{array}$ \\
\hline \multicolumn{2}{|l|}{ 3. Reduce anticipated reward } \\
\hline Remove targets & $\begin{array}{l}\text { Cash free travel } \\
\text { Phone cards } \\
\text { Women's refuges } \\
\text { Removable car phones }\end{array}$ \\
\hline Identify property & Property marking \\
\hline Reduce temptation & Rapid repair of vandalism \\
\hline Deny benefits & $\begin{array}{l}\text { Cleaning graffiti } \\
\text { Ink tags }\end{array}$ \\
\hline Disrupt markets & $\begin{array}{l}\text { Controls on advertisements } \\
\text { Checks on car boot sales/pawn shops }\end{array}$ \\
\hline \multicolumn{2}{|l|}{ 4. Remove excuses for crime } \\
\hline Set rules & $\begin{array}{l}\text { Codes of conduct } \\
\text { Rental agreements }\end{array}$ \\
\hline Alert conscience & Signs eg, consequences of staff assault \\
\hline Assist compliance & $\begin{array}{l}\text { Litter bins } \\
\text { Public lavatories } \\
\text { Make it easy to pay for goods }\end{array}$ \\
\hline Control drugs and alcohol & $\begin{array}{l}\text { Banning drinking in public places } \\
\text { Promotion of sensible drinking practices }\end{array}$ \\
\hline \multicolumn{2}{|l|}{ 5. Reduce provocation } \\
\hline Reduce frustration & $\begin{array}{l}\text { Queuing systems } \\
\text { Good customer service }\end{array}$ \\
\hline Avoid disputes & Separation of football fans \\
\hline Reduce temptation & $\begin{array}{l}\text { Fixed taxi fares } \\
\text { Controls on violent pornography } \\
\text { Banning paedophiles working with } \\
\text { children }\end{array}$ \\
\hline Neutralise peer pressure & $\begin{array}{l}\text { Disperse trouble making children in } \\
\text { schools }\end{array}$ \\
\hline Discourage imitation & Rapid repair of vandalism \\
\hline
\end{tabular}




\section{Figure 2}

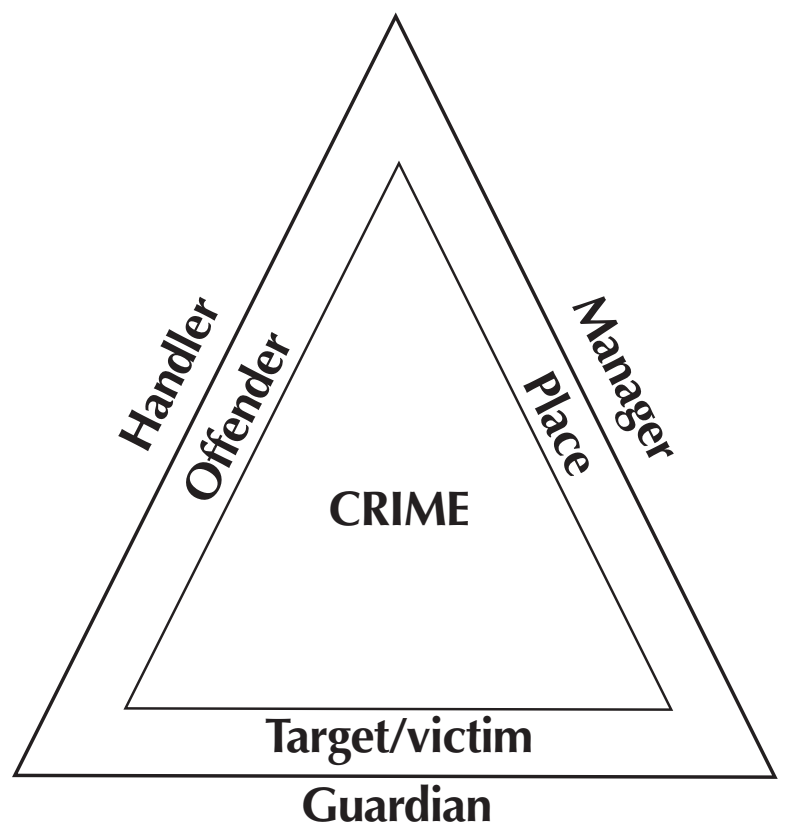

(From: Become a Problem Solving Analyst, Clarke \& Eck, 2003)

vulnerability of victim, offender and location.

In this way victim vulnerability can be counteracted by a capable guardian, which usually implies people protecting their own belongings or those of family members, friends etc. For the offender, a handler is someone who knows the offender well and who is in a position to exert some control over his/her action(s). Handlers may include parents, teachers and spouses. For the location a manager is a person who has some responsibility for controlling behaviour in a specific location.

In essence these techniques can be seen to enhance the NIM. For its part the NIM plays the critical role of allowing the prioritisation of and access to resources, and making sure those responsible for action are accountable to the tasking and coordinating group.

\section{ASSESSMENT AND HOW IT RELATES TO THE NATIONAL INTELIGENGE MODEL}

Learning about what works and passing that knowledge between those agencies responsible for reducing crime and disorder is critical. Problem solving should not be viewed as a linear process, but one that is continually revisited until a sustainable solution is established. The problem solving methodology puts significant emphasis on assessment which both HMIC and Audit Commission thematic inspections have shown is neglected, and although difficult is essential.

Within problem oriented approaches there are two main areas when it comes to assessment. Process evaluation is concerned with whether the initiative was implemented as intended whereas outcome evaluation is concerned with identifying the impact on crime/ disorder and determining whether the outcome is attributable to the interventions. There are many texts available on how to evaluate initiatives aimed at the police service and their partners. For example Passport to Evaluation: An introduction to evaluating crime reduction initiatives and projects is available from the Crime Reduction College. Similarly Ron Clarke and John Eck have recently published a guide called Becoming a ProblemSolving Analyst, which includes sections on evaluation. Some of the main issues that need considering are summarised in Table 3 (over).

The NIM has two analytical products dedicated to this task, which are the:

- Operational assessment: The purpose of this is an ongoing evaluation of the incoming information/intelligence/activity or operation.

- Results analysis: The NIM analytical technique serves the same purpose as that of 


\begin{tabular}{|c|c|}
\hline Evaluation stage & Questions to be addressed \\
\hline \multicolumn{2}{|l|}{ Process evaluation } \\
\hline $\begin{array}{l}\text { Identifying whether the project } \\
\text { was implemented and how }\end{array}$ & $\begin{array}{l}\text { Was the response implemented when it } \\
\text { was supposed to be? } \\
\text { Was it implemented in the right place? } \\
\text { Was the response appropriate for the } \\
\text { problem? } \\
\text { Was it targeted at the right group? } \\
\text { Was it implemented as planned? }\end{array}$ \\
\hline $\begin{array}{l}\text { Identifying whether enough } \\
\text { response was implemented }\end{array}$ & $\begin{array}{l}\text { Were there enough resources to fully } \\
\text { implement the response? } \\
\text { Was the response implemented for } \\
\text { enough time? } \\
\text { Was the response sufficiently intense? }\end{array}$ \\
\hline \multicolumn{2}{|l|}{ Impact evaluation } \\
\hline Measuring the impact & $\begin{array}{l}\text { What type of evaluation design is } \\
\text { appropriate? } \\
\text { Do you need a control group and if so } \\
\text { what type? } \\
\text { How often can you measure the problem? }\end{array}$ \\
\hline Attribution of impact & $\begin{array}{l}\text { What are the main process evaluation } \\
\text { results? } \\
\text { What are the impact results? } \\
\text { Did the problem decline after the } \\
\text { response? Did it decline at a faster rate? } \\
\text { What other explanations could have } \\
\text { caused the decline? } \\
\text { Are you confident that the response } \\
\text { caused the decline? }\end{array}$ \\
\hline
\end{tabular}

assessment in the SARA model. It evaluates and monitors impact on evaluates effectiveness of patrol strategies, crime reduction initiatives or particular methods of investigation.

However it can also be added that monitoring and evaluation runs through many other facets of the NIM for example TCG, which reviews the process and outcomes and holds action owners accountable for implementation. Also tactical assessment, which

\section{PROBLEM SOLVING AND THE NIM IN PRACTICE}

The following section deals with two examples of the process in practice.

\section{The class ' $A$ ' drugs problem}

In this actual case the strategic assessment provided to the strategic tasking and coordinating meeting provides intelligence about crimes emanating from the illegal supply of class A type drugs. As a result this particular problem is set as a force priority in the control strategy. At one of the quarterly reviews of the control strategy it is identified that there is an emerging trend of crack cocaine. The strategic TCG sets the intelligence requirement to detail the gaps in knowledge that need to be filled in order to assess the threats associated with this drug.

The force intelligence department uses many data sets from internal and external organisations and locally based analysts to provide the current situation, future threats and the implications for volume and organised crime. This could include the increase in the use of firearms, different trafficking routes, the emergence of organised crime groups, or a particular crime emerging to finance purchase (ie, mobile phone robbery). The analysis is then provided to the strategic TCG. 
The strategic TCG debates whether a strategic response is necessary and if so whether it should be in the form of further intelligence development, enforcement or prevention. Named people are given the responsibility for actions, such as contacting partners (eg, H.M. Customs and Excise or NCIS at a regional level). The strategic TCG allocates responsibility to the tactical TCG for carrying out the strategy and holds those implementing recommendations accountable. Tactical options may use force resources (ie, Major Crime Unit, test purchase operatives or the Press Office), or staff based within BCUs.

It may be that the strategic assessment shows the problem is acute on only a small number of the BCUs. These areas would conduct further analysis such as problem or target profiles to ascertain the exact nature of the problem. Again they could involve other partners (eg, housing or the benefits agency), to analyse or respond to the issue. The action plan is monitored through the tasking and coordinating process allowing an assessment of whether the outcomes or predictions actually occur.

\section{The NIM and anti-social behaviour}

There has been concern voiced about the capacity of the National Intelligence Model to accommodate low-level anti-social behaviour. Anti-social behaviour is a priority in each community safety strategy and it is the intention of the NIM that the model can encapsulate all levels of policing activity.

This means that even if antisocial behaviour is not set within the level 2 control strategy, this or similar issues can be set within the level 1 (BCU) control strategy. As such there is nothing to prevent these issues being addressed within strategic or tactical assessments and problem or target profiles being commissioned to outline activity in this area.

Further, as the tasking and coordinating process is predominantly to do with prioritising issues for the movement of resources, the process does not prevent officers who (with the knowledge of their supervisors) engage partners or initiate multiagency problem solving initiatives which are in line with locally set priorities, and which don't require extra resources. Not all problem identification will be initially triggered by the NIM. Individuals in their own working environments may, through experience or information sources, identify a problem. Indeed it is important that lower level issues do not overburden the tasking and coordinating process or consume all the time of trained analysts. As such it is only when the problem requires further resources or is felt to be a strategic issue for the $\mathrm{BCU}$ requiring coordination, that the extra benefits of the NIM are felt. That said it is important that police intelligence units have an awareness of what problems have been identified at a local level.

The Government, police and partnership response to anti-social behaviour has been a rapidly developing area in recent years. There are also developments on the issues around insecurity and antisocial behaviour through the 'restoring reassurance' agenda pursued by ACPO and supported by the Home Office. This agenda has demanded that forces piloting such approaches use the National Intelligence Model. Further the 'partnership business model' currently being developed nationally to assist within the field of community safety has also taken cognisance of the National Intelligence Model.

\section{CONELUSION}

The National Intelligence Model is a business model that not only enables police forces to work together with a level of common understanding but also greatly assists a problem solving approach. For its part the NIM provides a system that uses a common language, standard systems and operating procedures and which provides clear ownership and 
accountability. This should avoid some of the implementation problems that have been associated with problem solving approaches.

Similarly integrating a problem solving approach within the framework of the NIM clearly develops and enhances NIM products assisting the user to think more creatively around problems, with a view to providing sustainable solutions. In this way the philosophy adds value to the identification, analysis, response and evaluation of crime and disorder issues. Further, in this process partners are critical and must be viewed as an asset at all levels of the National Intelligence Model.

Indeed, partners are many and diverse, but although the NIM was devised with law enforcement agencies in mind, all those engaged in community safety will require co-ordinated systems and processes. The NIM offers a platform that enables partnership members to share information, identify problems, process information into intelligence and analyse that intelligence. This process can direct collaborative strategic and tactical tasking and co-ordinating and the influence of partners will lead to a more sustainable solution rather than an exclusively enforcement based response. The recent Home Office sponsored activity in relation to the partnership business model although using the SARA approach is fully compliant with the NIM.

In conclusion the National Intelligence Model, has the potential to provide a substantive platform upon which a problem solving approach can operate and evolve. However, as with all models it depends on its leaders to make sure the infrastructure and direction is in place, and depends on practitioners to willingly exploit those new methods in the operational setting.

\section{Acknowledgements}

Special thanks for assistance in preparing this paper go to: ACPO working group on 'problem solving', Police Standards Unit, Karen Bullock, National Intelligence Model Implementation team, Professor Gloria Laycock and The Jill Dando Institute.

\section{References}

Audit Commission (1999) Safety in numbers: A thematic inspection on Community Safety. London: Audit Commission.

Billsborough I \& Keay S (2002) 'A united approach' The Standard (i2 User Group) 24 (May-Sept) 8-9.
Bullock K \& Tilley N (2003) Crime Reduction and Problem-oriented Policing. Cullompton: Willan.

Clarke RV (1999) Hot Products: Understanding, Anticipating and Reducing Demand for Stolen Goods. Police Research Series Paper 112. London: Home Office.

Clarke R \& Eck J (2003) Become a Problem Solving Analyst. London: Jill Dando Institute of Crime Science, University College London.

Crawford A (1998) Crime Prevention and Community Safety. Harlow: Longman.

Goldstein H (1990) Problem Oriented Policing. New York, NY: McGraw-Hill.

Her Majesty's Inspectorate of Constabulary (2000) Calling Time on Crime: A thematic inspection on Crime and Disorder. London: Home Office.

John T \& Maguire M (2003) Crime Reduction and Problem Oriented Policing Rolling out the National Intelligence Model: key challenges. In: K Bullock \& N Tilley (2003) Crime Reduction and Problem-Oriented Policing. Cullumpton: Willan.

Kirby SJ (2003) Improving the effectiveness of partnerships in community safety. Community Safety Journal 2 (2) 4-9.

Read T \& Tilley N (2000) Not Rocket Science? Problem Solving and Crime Reduction. Crime Reduction Research Series 6. London: Home Office.

Scott M (2000) Problem Oriented Policing: Reflections on the First 20 Years. Washington, DC: Office of Community-Oriented Policing, US Department of Justice.

Tilley N (2003) Models of policing. In: T Newburn (Ed) Handbook of Policing. Collumpton: Willan. 